\title{
Remote control of pulmonary blood flow: Initial clinical experience
}

\author{
Antonio F. Corno, MD, FRCS, FETCS \\ Damien Bonnet, $M D^{b}$ \\ Nicole Sekarski, MD, FACPa \\ Daniel Sidi, MD ${ }^{\mathrm{b}}$ \\ Pascal Vouhé, MD, FECTS ${ }^{b}$ \\ Ludwig K. von Segesser, MD, FACS, FETCS ${ }^{a}$
}

From the Centre Hospitalier Universitaire Vaudois, ${ }^{a}$ Lausanne, Switzerland; and Hôpital Necker Enfants Malades, ${ }^{\text {b }}$ Paris, France.

Read at the Eighty-third Annual Meeting of The American Association for Thoracic Surgery, Boston, Mass, May 4-7, 2003.

Received for publication March 20, 2003; revisions received May 18, 2003; accepted for publication May 20, 2003.

Address for reprints: Antonio F. Corno, MD, FRCS, FETCS, Department of Cardiovascular Surgery, Centre Hospitalier Universitaire Vaudois (CHUV), 46 rue du Bugnon, CH 1011, Lausanne, Switzerland (E-mail: Antonio.Corno@chuv.hospvd.ch).

J Thorac Cardiovasc Surg 2003;126: $1775-80$

Copyright $(\underset{0}{ } 2003$ by The American Association for Thoracic Surgery

$0022-5223 / 2003 \$ 30.00+0$

doi:10.1016/j.jtcvs.2003.06.011
Objective: After positive experimental results were obtained with the FloWatch-RPAB (EndoArt S.A., Lausanne, Switzerland), an implantable device for pulmonary artery banding with telemetric control, it was tested in a prospective, multicenter clinical trial.

Methods: From June to September 2002, 6 patients with a mean age of 10.6 months (1-31 months) and a mean weight of $6.5 \mathrm{~kg}(3.5-11 \mathrm{~kg})$ underwent pulmonary artery banding with the implantation of the FloWatch-R-PAB device through median sternotomy (4 patients) or left thoracotomy ( 2 patients). The diagnoses were the following: univentricular heart (2 patients), complete atrioventricular septal defect (2 patients), ventricular septal defect (1 patient), and multiple ventricular septal defects with double aortic arch (1 patient). The associated procedures were atrioseptostomy with cardiopulmonary bypass ( 2 patients), closure of patent ductus arteriosus ( 2 patients), and division of double aortic arch (1 patient).

Results: In a mean follow-up of 7 months (6-9 months), there were no early or late deaths, reoperations, or device-related complications. A mean of 5 regulations per patient (range 2-14) were required to adjust the tightening of the pulmonary artery banding, $50 \%$ (15/30) within the first postoperative week, 20\% (6/30) during the second week, and 30\% (9/30) within 8 months after surgery. In $70 \%$ (21/30) of the cases, the regulation was required to further narrow the pulmonary artery, and in $30 \%(9 / 30)$ of the cases, the regulation was required to release the pulmonary artery.

Conclusions: The initial trial confirmed the adequate functioning of the FloWatchR-PAB device as telemetrically adjustable pulmonary artery banding. Repeated pulmonary artery banding adjustments, dictated by the clinical need in all patients even weeks after surgery, were accomplished without need for reoperation or invasive procedures. In children requiring pulmonary artery banding, the therapeutic strategies can be expanded by this promising technology. This device should be particularly indicated in patients with transposition of the great arteries requiring left ventricular retraining.

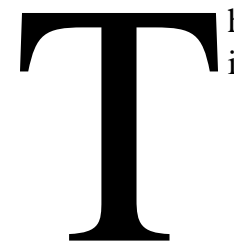

he indication for pulmonary artery banding $(\mathrm{PAB})$ is currently limited by several factors:

1. Difficulty in determining the optimal band, because minor changes in diameter have a large impact on blood flow and pressure gradient across the band site.

2. Influence of several perioperative variables with mutual interference related to general anesthesia with positive pressure ventilation and chest opening, particularly with thoracotomy. ${ }^{1}$ 


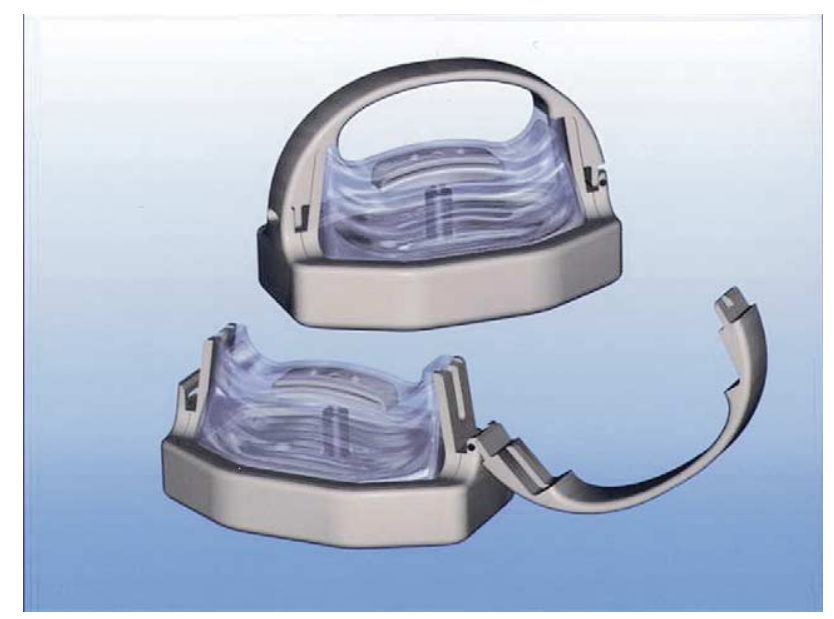

Figure 1. The FloWatch-R-PAB (EndoArt S.A., Lausanne, Switzerland) device in clipped and unclipped position.

3. Age-related variability of the ventricular adaptive response, particularly in "functionally" univentricular hearts ${ }^{2}$ and transposition of the great arteries requiring retraining of a low pressure left ventricle in view of arterial switch operation. ${ }^{3}$

4. Difficulty in sufficiently tightening the banding in children with pulmonary hypertension.

5. Flow adjustment in children with congenital heart defects with increased pulmonary blood flow, with or without cyanosis, in which the PAB is successful in controlling the distal pressure but overflow persists.

6. Frequent need for repeated operations to adjust the band perimeter, including children outgrowing a banding that is rapidly becoming too tight.

7. Long periods of intensive respiratory or pharmacologic interventions to control the pulmonary blood flow. ${ }^{3}$

8. Frequent need for a reconstruction of the pulmonary artery at the moment of the conventional debanding for surgical repair.

To overcome these difficulties, several attempts have been made to find an adjustable PAB that allows external regulation during the hours or days after the surgical procedure. $^{4-19}$ A MEDLINE research for "adjustable PAB" revealed 16 different techniques reported within the last 10 years. However, none of these techniques resulted in a device allowing a precise, long-term, noninvasive adjustment of pulmonary blood flow in both ways, with repeated narrowing and releasing of the pulmonary artery.

Therefore, we decided to perform an experimental study in mini-pigs with the FloWatch-R-PAB (EndoArt S.A., Lausanne, Switzerland), an implantable, telemetrically controlled, battery-free device (Figure 1) that allows repeated progressive occlusion and reopening of the device through a remote control at the required percentage of occlusion. ${ }^{20}$
The change in the adjustable area is obtained by a piston driven by an incorporated electric micromotor. The concave form of the adjustable area was chosen so that during compression the area changes but the perimeter of the pulmonary artery remains unchanged, which is optimal for long-term use (ie, reopening after several weeks of pulmonary artery compression). The adjustable area in the fully open position corresponds to a PAB with a perimeter of 30 $\mathrm{mm}$, and in the fully closed position to a PAB with a perimeter of $23 \mathrm{~mm}$. The adjustment is performed through an external control unit that delivers the energy and commands (through the antenna) to drive the micro-engine. The size of the device is $26 \times 18 \times 18 \mathrm{~mm}$.

Because of the positive long-term results of the experimental study with this new adjustable $\mathrm{PAB},{ }^{21,22}$ we decided to perform a prospective, multicenter clinical trial.

\section{Methods}

After approval by the institutional ethical committee of each hospital, informed consent was obtained from the parents or legal guardians of all children enrolled in the clinical trial.

From June to September 2002, 6 patients with a mean age of 10.6 months (range 1-31 months) and a mean body weight of 6.5 $\mathrm{kg}$ (range 3.5-11 kg) underwent PAB with the FloWatch-R-PAB device implantation. The technical characteristics of the device have been reported in detail. ${ }^{20-22}$

The diagnosis was univentricular heart in 2 patients (hypoplastic mitral valve and intact atrial septum in 1 patient and right isomerism, dextrocardia, total anomalous pulmonary venous connection, and patent ductus arteriosus in 1 patient), complete atrioventricular septal defect in 2 patients (left ventricular dominance and patent ductus arteriosus in 1 patient), isolated ventricular septal defect in 1 patient, and multiple ventricular septal defects and double aortic arch in 1 patient. All infants presented with systolic pulmonary artery pressure at systemic levels. The 2 children who came to our observation after infancy at 19 and 31 months of age with complete atrioventricular septal defect and isolated ventricular septal defect, respectively, presented with elevated pulmonary vascular resistance nonresponsive to the routine pulmonary vasodilators, precluding first-stage repair.

The implantation of the FloWatch-R-PAB device was performed through median sternotomy (4 patients) or left thoracotomy ( 2 patients) according to the need for associated surgical procedures and the surgeon's preference.

The surgical technique for the implantation of the FloWatchR-PAB device was exactly the same as for conventional PAB, with minimal dissection to encircle the pulmonary artery with the clip of the FloWatch-R-PAB device in an open position. Then the device was clipped, and the pericardium and chest were closed in routine fashion.

Associated procedures were atrioseptostomy with cardiopulmonary bypass in 2 patients ( 1 patient with associated division of patent ductus arteriosus), closure of patent ductus arteriosus in 1 patient, and division of double aortic arch in 1 patient.

The intraoperative and postoperative device-related data were recorded, in particular with regard to the clinical follow-up, need 

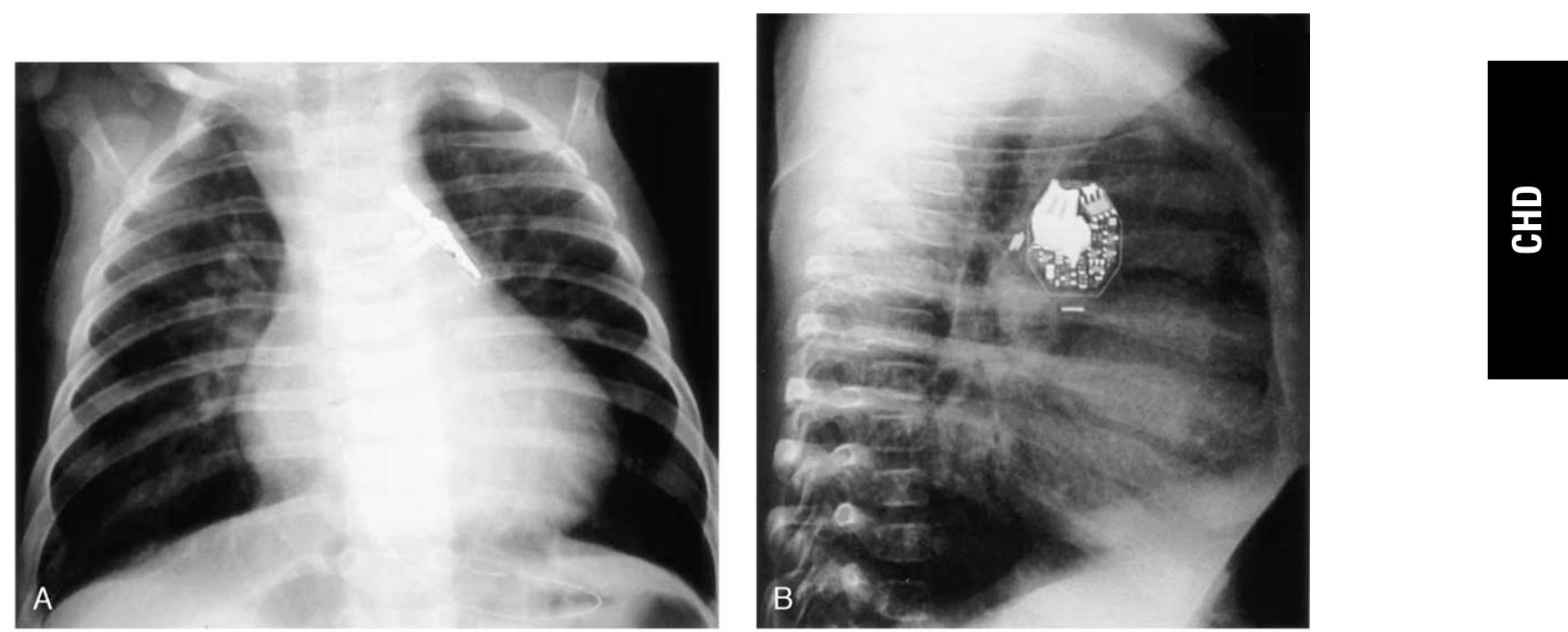

Figure 2. Postoperative chest $x$-ray film in the anteroposterior $(A)$ and lateral $(B)$ views showing the device in place.

for telemetric PAB adjustments, reoperations, or device-related complications.

\section{Results}

The implantation of the device was easy in all cases, with the entire surgical procedure lasting less than 40 minutes in the 2 patients not requiring associated procedures. The reduced time needed for PAB obtained with the FloWatch-R-PAB device is justified by the possibility of telemetric adjustment of the tightening of the PAB after chest closure.

All children were extubated within the first 24 hours after surgery. The median stay in the intensive care unit was 1 day, with 4 patients staying 1 day, 1 patient staying 3 days, and a neonate with Down syndrome and association of a major upper airway problem requiring endoscopic supraglottoplasty staying 29 days.

There were no early or late deaths, reoperations, or device-related complications in a mean follow-up of 7 months (range 6-9 months).

After the first telemetric regulation of the FloWatch-RPAB device on the same day of surgery, a mean of 5 regulations per patient (range 2-14) were required to adjust the tightening of the PAB to the clinical needs; $50 \%$ (15/30) of telemetric regulations were required within the first postoperative week, $20 \%$ (6/30) during the second week, and $30 \%(9 / 30)$ between 3 weeks and 8 months after surgery. In all cases, tightening and releasing of the pulmonary artery were performed under control with Doppler echocardiography, with the same correspondence between the percentage of occlusion and trans-banding pressure gradient as observed in the experimental study. ${ }^{22}$ Figure 2 shows the unusual postoperative chest $\mathrm{x}$-ray film.
In $70 \%(21 / 30)$ of cases, the regulation was required to further narrow the pulmonary artery, and in 30\% (9/30) of cases, the regulation was required to release the pulmonary artery. In 2 cases, the telemetric release of the pulmonary artery was required on an emergency basis because of arterial oxygen desaturation and bradycardia. We appreciated the capability of obtaining full release of the pulmonary artery within less than 60 seconds allowed by the device.

During the relatively short follow-up period, only the child with isolated ventricular septal defect underwent surgical repair 3 months after the implantation of the FloWatch-R-PAB device; the procedure was uneventful, with uncomplicated device removal and without need for pulmonary artery reconstruction.

\section{Discussion}

The main technical problem encountered in PAB is the difficulty in determining the optimum perimeter of the band. Both turbulent and viscous losses are highly dependent on the radius of the vessel; therefore, a minor change in diameter has a large impact on blood flow and pressure gradient across the band site.

Moreover, the effects of the banding on pulmonary artery pressure and flow are influenced by clinical variables with mutual interference: heart rate and contractility, arterial $\mathrm{Po}_{2}$ and $\mathrm{PCO}_{2}$, acid-base status, hematocrit, and balance between systemic and pulmonary resistance. ${ }^{1}$ Substantial changes occur to all these variables, particularly within the first hours and days after surgery, with particular instability within the first few hours or days after the operation. ${ }^{1}$

It is therefore very difficult to predict the effectiveness of a $\mathrm{PAB}$ with the band applied in an almost instantaneous 
fashion and the decision about the adequacy of the tightening based on few parameters (systemic and pulmonary artery pressure, systemic oxygen saturation, and expired $\mathrm{CO}_{2}$ ) followed by only a short interval before the chest closure. $^{1}$

Because of all these reasons, surgical operations may be required to adjust the band perimeter, or a long period with intensive respiratory and pharmacologic interventions may be needed to control the pulmonary blood flow. ${ }^{3}$

The need for adjustable PAB has been confirmed by the extensive experimental and clinical research performed in different institutions ${ }^{4-19}$ that has not procured a reliable device capable of noninvasively narrowing and releasing the pulmonary artery days or weeks after surgery.

With all these problems in mind, we adopted the idea of a device allowing PAB through a fast-track surgical procedure, with the effective possibility of telemetric control of the pulmonary blood flow and the trans-banding pressure gradient, even a long time after surgical implantation. In our experimental study, we demonstrated the adequate functioning of the device with the capability of narrowing and releasing the pulmonary artery by telemetric control up to 14 months after implantation. ${ }^{21,22}$

Another advantage of this technique observed in our experimental study is the maintenance of normal morphology and histology of the pulmonary artery wall in conjunction with the narrowing, allowing for full distension of the pulmonary artery after removal of the device, without stenosis and therefore without pulmonary artery reconstruction. $^{22}$ In our relatively short clinical experience, only 1 child underwent FloWatch-R-PAB device removal because of the surgical repair, and even if the interval was short (3 months), there was no need for any procedure to fully dilate the pulmonary artery.

The main clinical advantages of PAB with the FloWatchR-PAB device, forecasted as potential advantages when we reported the experimental results ${ }^{21,22}$ and the first clinical application $^{23}$ (and confirmed by the initial observations in this multicenter clinical trial), are the following: fast-track surgical procedure, effective control of pulmonary blood flow, no banding-related reoperations, and simplified postoperative course.

As a consequence of these advantages, a reduction of mortality and morbidity can be expected when comparing a substantial number of patients with this new approach with a homogeneous group of patients with conventional banding. We realize that the major limit of our clinical trial is the absence of prospective randomization versus the conventional treatment, but in consideration of the experimental data and the problems encountered in conventional banding, as soon as the FloWatch-R-PAB device became clinically available we all agreed that children requiring a PAB should be able to take advantage of this already available technique.

Nevertheless, we reviewed the data of the patients who underwent conventional PAB at Centre Hospitalier Universitaire Vaudois, Lausanne, Switzerland, before the clinical availability of the FloWatch-R-PAB device. Among 11 consecutive children, there was an incidence of $45.5 \%$ (5/ 11) of required reoperations to adjust the tightening of the band, a mean duration of mechanical ventilation of 9.7 days (range 2-28 days), and a mean stay in the intensive care unit of 19.4 days (range 4-41 days) (unpublished data; Corno, 2002). These data are worse than the initial clinical observations in our trial, even if this historical group included a substantial number of patients requiring left ventricular retraining because of late referral for arterial switch. ${ }^{24}$

If future clinical studies with FloWatch-R-PAB device implantation confirm our initial results and clinical benefits, this device will represent a major change in the management of children requiring PAB, particularly for the most complex pathophysiologic situations, such as univentricular hearts requiring preparation for total cavopulmonary connection and transposition of the great arteries requiring left ventricular retraining because of late referral. The size of the currently available device limits the clinical application to children weighing 15 to $20 \mathrm{~kg}$, and therefore a larger size needs to be developed for older children and adolescents, particularly for left ventricular retraining.

The cost of this evolving technology is unknown because currently the device is only available for the multicenter clinical trial. When it becomes commercially available, the price will need to be balanced against the effective reduction of costs brought about by the shorter stay in the intensive care unit and hospital and the reduced number of reoperations.

Finally, the indications for PAB could be expanded to adapt the therapeutic strategies to this promising technology.

\section{Addendum}

Since the submission of this article, the multicenter clinical trial has been extended to 14 patients weighing between 3.5 and $20 \mathrm{~kg}$. There have been no deaths or device-related reoperations. Four patients have undergone intracardiac repair with device removal, and none required a reconstruction of the pulmonary artery.

\section{References}

1. Corno AF. Revised pulmonary artery banding. Ann Thorac Surg. 2000;69:1295-6.

2. Tchervenkov CI, Shum-Tim D, Beland MJ, Jutras L, Platt R. Single ventricle with systemic obstruction in early life: comparison of initial pulmonary artery banding versus the Norwood operation. Eur Cardiothorac Surg. 2001;19:671-7.

3. Wernovsky G, Giglia TM, Jonas RA, Mone SM, Colan SD, Wessel DL. Course in the intensive care unit after "preparatory" pulmonary 
artery banding and aortopulmonary shunt placement for transposition of the great arteries with low left ventricular pressure. Circulation. 1992;86:II133-9.

4. Ahmadi A, Rein J, Hellberg K, Bastanier C. Percutaneously adjustable pulmonary artery band. Ann Thorac Surg. 1995;60:S520-2.

5. Assad RS, Cardarelli M, Abduch MC, Aiello VD, Maizato M, Barbero-Marcial M, et al. Reversible pulmonary trunk banding with a balloon catheter: assessment of rapid pulmonary ventricular hypertrophy. J Thorac Cardiovasc Surg. 2000;120:66-72.

6. Bonnet D, Sidi D, Vouhé PR. Absorbable pulmonary artery banding in tricuspid atresia. Ann Thorac Surg. 2001;71:360-1.

7. Dajee H, Benson L, Laks H. An improved method of pulmonary artery banding. Ann Thorac Surg. 1984;37:254-7.

8. Dabritz SH, Sachweh JS, Tiete AR, Engelhardt W, von Bernuth G, Messmer BJ. Experience with an adjustable pulmonary artery banding device in two cases: initial success-midterm failure. Thorac Cardiovasc Surg. 1999;47:51-2.

9. Dias CA, Assad RS, Caneo LF, Abduch MCD, Aiello VD, Dias AR, et al. Reversible pulmonary trunk banding. II. An experimental model for rapid pulmonary ventricular hypertrophy. J Thorac Cardiovasc Surg. 2002;124:999-1006.

10. Higashidate M, Beppu T, Imai Y, Kurosawa H. Percutaneously adjustable pulmonary artery band. An experimental study. J Thorac Cardiovasc Surg. 1989;97:864-9.

11. Le Bret E, Bonhhoeffer P, Folliguet TA, Sidi D, Laborde F, de Leval $\mathrm{MR}$, et al. A new percutaneously adjustable, thoracoscopically implantable, pulmonary artery banding: an experimental study. Ann Thorac Surg. 2001;72:1358-61

12. Muraoka R, Yokota M, Aoshima M, Nomoto S, Kyotu I, Kobayashi A, et al. Extrathoracically adjustable pulmonary banding. J Thorac Car diovasc Surg. 1983;86:582-6.

13. Nahs R, Mundth ED, Ross B, Austen WG. Adjustable instrument for pulmonary artery banding. Description of instrument and technique of application. J Thorac Cardiovasc Surg. 1972;63:732-4.

14. Park SC, Griffith BP, Siewers RD, Hardesty RL, Ladowski J, Zoltun RA, et al. A percutaneously adjustable device for banding of the pulmonary trunk. Int J Cardiol. 1985;9:477-84.

15. Peek GJ, Arsiwala SS, Chan KC, Hickey MS. Absorbable pulmonary artery band. Ann Thorac Surg. 1997;64:539-41.

16. Schlensak C, Sarai K, Gildein HP, Beyersdorf F. Pulmonary artery banding with a novel percutaneously, bi-directional adjustable device. Eur J Cardiothorac Surg. 1997;12:931-3.

17. Solis E, Heck CF, Seward JB, Kaye MP. Percutaneously adjustable pulmonary artery band. Ann Thorac Surg. 1986;41:65-9.

18. Vince DJ, LeBlanc JG, Culham JAG, Taylor GP. A dilatable prosthesis for banding the main pulmonary artery: human clinical trials. Int J Card Imaging. 1996;12:205-12.

19. Warren ET, Heath BJ, Brand WW. A staged expanding pulmonary artery band. Ann Thorac Surg. 1992;54:240-2.

20. Fridez P, Jordan A, Montavon JC, Stergiopulos N. FloWatch: an implantable device for telemetric control of flow after pulmonary artery banding. Cardiovasc Eng. 2002;7:51.

21. Corno AF, Fridez P, von Segesser LK, Stergiopulos N. A new implantable device for telemetric control of pulmonary blood flow. Interactive Cardiovasc Thorac Surg. 2002;1:46-9.

22. Corno AF, Sekarski N, Bernath MA, Payot M, Tozzi P, von Segesser LK. Pulmonary artery banding: long-term telemetric adjustment. Eur J Cardiothorac Surg. 2003;23:317-22.

23. Corno AF, Sekarski N, von Segesser LK. Remote control of pulmonary blood flow: a dream comes true. Swiss Med Wkly. 2002;132: 423-4.

24. Corno AE, Hurni M, Payot M, Sekarski N, Tozzi P, von Segesser LK Adequate left ventricular preparation allows for arterial switch despite late referral. Cardiol Young. 2003;13:49-52.

\section{Discussion}

Dr Duke E. Cameron (Baltimore, Md). Thank you, Dr. Corno, for this fine presentation and for sharing your article with me before the meeting. You and your group have presented the first clinical series of a totally implantable, remote-controlled, bidirectionally adjustable $\mathrm{PAB}$ with very encouraging results.

An adjustable band has long been sought by some congenital heart surgeons, who as a group all know that every PAB is perfect in the operating room and every band is either too loose or too tight by the time the child is back in the intensive care unit. The optimum band parameter is thus a moving target. So adjustability has obvious appeal.

You have shown that your device works, that it is safe, and that adjustability persists for approximately 1 year, but the follow-up is brief, and having said that adjustability is desirable, we are still uncertain if this relatively expensive and complex device provides a substantial clinical advantage in most patients over a single shoestring of siliconized Teflon. I suspect that further experience will reflect on this, but I might predict that most patients with PAB do not require multiple adjustments.

You mentioned in your article that reinterventions for tightening or loosening with conventional banding were required in $45 \%$ of patients in your institution, which I would think would be a bit high. In fact, most infants are well served by a single application of a band without adjustment and then early progression to either definitive total correction or a cavopulmonary shunt.

I expect the greatest use of this device will be seen in that ever-diminishing group of patients who need left ventricular retraining for a staged arterial switch or perhaps in a small select group who are undergoing experimental treatments for Eisenmenger's. In both of these groups there is a definite need for slow, progressive tightening of the band over time.

I have 3 questions. First, could you give us a rough idea of the cost of this device?

Second, although I meant to ask you why this band causes less morphologic and histologic distortion than a conventional band, I see that I think you have explained that the band flattens the PA rather than crimps it. But I wonder if you could address a different question. The device itself is fairly bulky, and I could imagine in a small infant, in certain anatomic subtypes with a pulmonary artery directly posterior to the aorta, that the device may be difficult to fit in the mediastinum without compressing adjacent structures.

And finally, do you really see this being used in all patients, or do you suspect that there are just certain patients for whom the adjustability is highly desirable?

Finally, do you have some thoughts about applications of this device outside of cardiac surgery?

Dr Corno. Thank you very much, Dr. Cameron, for your very kind comments. To answer your first question about the price, the device will be commercially available at the beginning of June in countries without Food and Drug Administration regulations, and the price should be in the range of a pacemaker price. Of course, you can easily say that a polytetrafluoroethylene or Teflon band is much cheaper, but I believe that the price should be balanced against the reduced stay in the intensive care unit and hospital, mechanical ventilation time, and cost of reoperations and complications. So this should pay for the price of the device.

Regarding the question of the morphology of the pulmonary artery, when we removed the device, and this was up to 6 months or even 14 months after the implant, there was a full reexpansion of the pulmonary artery in all 16 mini-pigs of the experimental 
study. We also performed a histology in all of them, and there was normal morphology of the pulmonary artery. We have no explanation but only speculation to offer, and that is because the pulmonary artery, instead of being exposed to a circular restriction as in a conventional band, is squeezed, as you have seen, with a banana shape, and this, by reducing the cross-sectional area but not the circumference, is adequate to reduce the pressure and the flow distal to the device but not enough to induce a fibrosis. These observations have been confirmed in the clinical experience. So far, none of the patients have required reconstruction of the pulmonary artery after device removal.

Regarding the size, you are right, it is quite bulky, but the length is $26 \mathrm{~mm}$, and the other 2 dimensions are $18 \mathrm{~mm}$ each. We implanted this device in the smallest mini-pig of $3.2 \mathrm{~kg}$. The smallest patient was also $3.2 \mathrm{~kg}$. We did not observe any compression of coronaries or lung in any of the mini-pigs or patients, provided that the box of the device was left on the other side of the aorta, of course. We suggest, anyway, that the device be applied in children weighing $3.5 \mathrm{~kg}$ and not smaller than that.

Regarding the last comment (if this device is indicated in all patients), we started this study only because very complex cases are referred to our tertiary center. We are pushing toward an early repair, so we do not perform any more banding in regular or simple ventricular septal defect or atrioventricular septal defects.

In the period before this device was available, we were faced with a very complex group of patients with transposition of great arteries and intact ventricular septum, referred for left ventricular retraining before arterial switch between 6 months and 2 years of age, univentricular heart at 1 or 2 years of age with pulmonary hypertension, or ventricular septal defect or atrioventricular septal defect at 3, 4, or more years of age with high pulmonary vascular resistance not responsive to conventional vasodilators. I believe this group is very difficult to manage with conventional banding; at least in our experience, the postoperative course was a nightmare. Particularly for the univentricular heart or left ventricular retraining (recently published in Cardiology in the Young), we had to go back to adjust the banding or we had the patient on mechanical ventilation in the intensive care unit for a long period of time.

Dr Renato S. Assad (Sao Paulo, Brazil). First, I want to congratulate your group for pursuing the research and develop- ment on a very ingenious adjustable PAB device. Since 1991, we have been studying reversible $\mathrm{PAB}$ in young goats to assess subpulmonary ventricle retraining. The prototype used in our experiments, similar to our previous prototype described in an article published last year in The Journal of Thoracic and Cardiovascular Surgery, is a silicone-made PAB hydraulic cuff system (Silimed Inc, Rio de Janeiro, Brazil). The main difference is that the banding ring is a smaller C-shape flat tape, less than $2 \mathrm{~mm}$ (thick) $\times 6 \mathrm{~mm}$ (width). Its outer surface consists of 1-mm rigid silicone, which keeps it from deforming. The inner surface has a deformable layer of silicone, which expands (compressing the lumen of the vessel) according to the volume injected into a circular reservoir made of self-sealing silicone, in which the base includes a ceramic plate. This auto-sealing button is implanted subcutaneously and permits precise inflation or deflation of the banding ring percutaneously in young goats.

My main concern is related to the cost-benefit ratio. Our device should cost much less than a pacemaker, and it is disposable. I was wondering how much the FloWatch-R-PAB device would cost compared with our adjustable hydraulic cuff system? Second, the way it compresses the lumen of the pulmonary trunk is elliptical rather than circular. In addition, it takes too much room around the pulmonary artery. I would like to know if the change in the pulmonary trunk shape imposes any initial gradient after placing a loose device?

Dr Corno. Thank you for your questions. Of course I was aware of your device, first because I read the article, and second because you gave me a sample 2 years ago in another meeting, and that is why I started to study our system. I believe we need a really adjustable device that is able to not only narrow but also release the pulmonary artery, which is not feasible, to my knowledge, with any other device. We demonstrated we can reopen the pulmonary artery even 14 months after the implant, and no other device is able to do that.

I agree with you about the problem of the cost, but again, if the intensive care unit stay can be reduced a few days, this will pay the price for the device.

Regarding the size, as I told you, there is a certain space occupation, but we never had any compression of any vital structure with any of the devices in experimental or clinical application. 